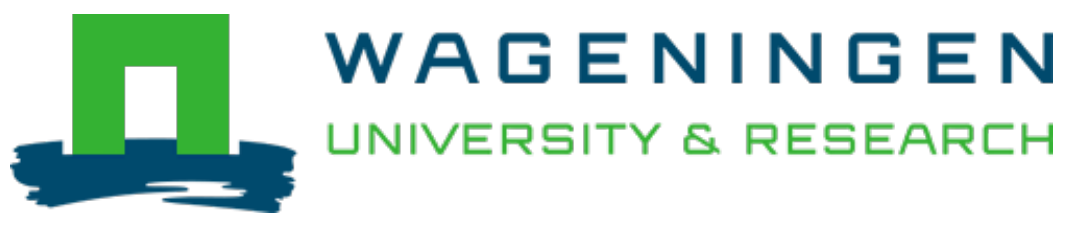

\title{
Evaluating impacts of bottom trawling and hypoxia on benthic communities at the local, habitat, and regional scale using a modelling approach
}

\author{
ICES Journal of Marine Science \\ Denderen, P.D.; Bolam, S.G.; Friedland, R.; Hiddink, J.G.; Norén, K. et al \\ https://doi.org/10.1093/icesjms/fsz219
}

This article is made publicly available in the institutional repository of Wageningen University and Research, under the terms of article $25 \mathrm{fa}$ of the Dutch Copyright Act, also known as the Amendment Taverne. This has been done with explicit consent by the author.

Article 25 fa states that the author of a short scientific work funded either wholly or partially by Dutch public funds is entitled to make that work publicly available for no consideration following a reasonable period of time after the work was first published, provided that clear reference is made to the source of the first publication of the work.

This publication is distributed under The Association of Universities in the Netherlands (VSNU) 'Article $25 \mathrm{fa}$ implementation' project. In this project research outputs of researchers employed by Dutch Universities that comply with the legal requirements of Article $25 \mathrm{fa}$ of the Dutch Copyright Act are distributed online and free of cost or other barriers in institutional repositories. Research outputs are distributed six months after their first online publication in the original published version and with proper attribution to the source of the original publication.

You are permitted to download and use the publication for personal purposes. All rights remain with the author(s) and / or copyright owner(s) of this work. Any use of the publication or parts of it other than authorised under article $25 \mathrm{fa}$ of the Dutch Copyright act is prohibited. Wageningen University \& Research and the author(s) of this publication shall not be held responsible or liable for any damages resulting from your (re)use of this publication.

For questions regarding the public availability of this article please contact openscience.library@,wur.nl 


\title{
ICES Journal of
}

\section{Original Article}

\section{Evaluating impacts of bottom trawling and hypoxia on benthic communities at the local, habitat, and regional scale using a modelling approach}

\author{
P. D. van Denderen ${ }^{1}$, S. G. Bolam ${ }^{2}$, R. Friedland ${ }^{3}$, J. G. Hiddink ${ }^{4}$, K. Norén ${ }^{5}$, A. D. Rijnsdorp ${ }^{6}$, \\ M. Sköld ${ }^{5}$, A. Törnroos ${ }^{7}$, E. A. Virtanen ${ }^{8}$, and S. Valanko ${ }^{9}$ \\ ${ }^{1}$ Centre for Ocean Life, Danish Technical University Aqua, Kongens Lyngby, Denmark \\ ${ }^{2}$ Lowestoft Laboratory, Centre for Environment, Fisheries and Aquaculture Science (CEFAS), Pakefield Road, Lowestoft, Suffolk NR33 OHT, UK \\ ${ }^{3}$ Leibniz-Institut für Ostseeforschung Warnemünde, Rostock, Germany \\ ${ }^{4}$ School of Ocean Sciences, Bangor University, Menai Bridge, UK \\ ${ }^{5}$ Department of Aquatic Resources, Institute of Marine Research, Swedish University of Agricultural Sciences, Lysekil, Sweden \\ ${ }^{6}$ Wageningen Marine Research, Wageningen University, IJmuiden, The Netherlands \\ ${ }^{7}$ Environmental and Marine Biology, Åbo Akademi University, Turku, Finland \\ ${ }^{8}$ Finnish Environment Institute, Marine Research Centre, Helsinki, Finland \\ ${ }^{9}$ International Council for the Exploration of the Sea, Copenhagen, Denmark
}

*Corresponding author: tel: +45358833 00; e-mail: pdvd@aqua.dtu.dk.

van Denderen, P. D., Bolam, S. G., Friedland, R., Hiddink, J. G., Norén, K., Rijnsdorp, A. D., Sköld, M., Törnroos, A., Virtanen, E. A., and Valanko, S. Evaluating impacts of bottom trawling and hypoxia on benthic communities at the local, habitat, and regional scale using a modelling approach. - ICES Journal of Marine Science, 77: 278-289.

Received 24 January 2019; revised 24 October 2019; accepted 26 October 2019; advance access publication 20 November 2019.

Bottom trawling disturbance and hypoxia are affecting marine benthic habitats worldwide. We present an approach to predict their effects on benthic communities, and use the approach to estimate the state, the biomass relative to carrying capacity, of the Baltic Sea at the local, habitat, and regional scale. Responses to both pressures are expected to depend on the longevity of fauna, which is predicted from benthic data from 1558 locations. We find that communities in low-salinity regions mostly consist of short-lived species, which are, in our model, more resilient than those of the saline areas. The model predicts that in $14 \%$ of the Baltic Sea region benthic biomass is reduced by at least $50 \%$, whereas an additional $8 \%$ of the region has reductions of $10-50 \%$. The effects of hypoxia occur over larger spatial scales and lead to a low state of especially deep habitats. The approach is based on a simple characterization of the benthic community, which comes with high uncertainty, but allows for the identification of benthic habitats that are at greatest risk and prioritization of management actions at the regional scale. This information supports the development of sustainable approaches to manage impact of human activities on benthic ecosystems.

Keywords: benthic fauna, bottom fishing, ecosystem-based management, human pressures, impact assessment, oxygen deficiency, seabed disturbance

\section{Introduction}

Bottom trawling disturbance and hypoxia cause widespread impacts on marine ecosystems, changing the physical and physico-chemical characteristics of the seabed and their associated benthic invertebrate communities (Gray et al., 2002; Sciberras et al., 2016; Hiddink et al., 2017). Bottom trawl fisheries account for $>25 \%$ of the global fisheries capture and have a large spatial footprint, especially in continental shelves (Eigaard et al., 2017; Amoroso et al., 2018; Watson and Tidd, 2018). Hypoxia of sea bottom waters due to eutrophication is becoming increasingly widespread around the world and is estimated to affect $\sim 0.25$ million square kilometres of shallow regional seas and coastal habitats (Diaz and Rosenberg, 2008; Breitburg et al., 2018). 
Fishing vessels using bottom trawls physically disturb the seabed by towing a gear (e.g. trawls, dredges) over the seafloor that damages and/or kills benthic organisms, reducing species biomass, abundance, and richness (de Groot, 1984; Collie et al., 2000; Sciberras et al., 2018). The effects of trawling are most pronounced in long-lived benthic organisms as these typically take longer to recover after a trawling event (Kaiser et al., 2018; Hiddink et al., 2019). Frequently trawled areas have been shown to exhibit reductions in the biomass of long-lived organisms (Tillin et al., 2006; van Denderen et al., 2015).

Eutrophication-induced hypoxia, oxygen deficiency, and anoxia, severe hypoxia, i.e. absence of dissolved oxygen, in bottom waters results from both natural processes and anthropogenic activity. The impact of oxygen deficiency in benthic species depends on the severity of hypoxia. Low, but non-lethal, oxygen concentrations result in various behavioural changes. Mobile organisms may move away from or avoid hypoxic areas, while behavioural responses of sessile species may manifest as alterations to feeding and bioturbation rates (Villnäs et al., 2012). Further declines in oxygen concentrations lead to mortality depending on speciesspecific sensitivities and the magnitude and extent of hypoxia, with complete faunal depletion being observed in very low oxygen concentrations $\left(\sim 0.5 \mathrm{ml} \mathrm{O}_{2} \mathrm{l}^{-1}\right)$ and anoxic conditions (Diaz and Rosenberg, 1995). Low oxygen concentrations, from natural processes or anthropogenic activity, can be episodic or seasonal in many estuaries, fjords, or along open coasts, while more-orless permanent in some isolated basins and shallow seas (Levin et al., 2009).

In an ecosystem such as the Baltic Sea, bottom trawling and hypoxia already act on a large spatial scale, potentially affecting entire habitats and the ecosystem. Bottom trawling mainly occurs in the western and southern parts of the Baltic Sea (ICES, 2017), where otter trawls target demersal fish such as cod, brill, turbot, plaice, and flounder. In such gears, the otter boards (trawl doors) penetrate the sediment, whereas the trawl sweeps and the trawl ground gear mainly impact the surface layers of the sediment (Eigaard et al., 2016). Hypoxic and anoxic conditions are predominantly observed further north in the offshore waters of the Baltic Sea. The area with low oxygen conditions has greatly expanded over the last decades due to eutrophication (Conley et al., 2009; Carstensen et al., 2014). Even though bottom trawling and hypoxia are largely disconnected in space, an assessment of their overall impact is needed to identify benthic habitats that are at greatest risk and to facilitate the development of joint management measures at a regional scale (Korpinen et al., 2012).

We developed an assessment methodology that quantitatively predicts benthic community impact from trawling disturbance and low oxygen concentrations. Impact is predicted using a population dynamic growth model (Mazor et al., 2017; Pitcher et al., 2017) that assumes that mortality on benthic communities is pressure-specific, whereas the responses (recovery) of benthic communities to these pressures are dependent on faunal longevity (maximum lifespan) (Rijnsdorp et al., 2016, 2018; Hiddink et al., 2019). Using the model, we estimate the state of the Baltic Sea benthic macrofauna community as a whole and for two specific functional groups, i.e. suspension-feeders and sediment bioturbators. We validate part of the model predictions in two areas of the Baltic Sea by comparing benthic community responses over gradients of trawling intensity. Finally we derive an overall state of the benthic habitat, which is illustrated in a map and further summarized per habitat type.

\section{Methods}

\section{Method outline}

We examined how faunal longevity, defined as the longevitybiomass composition of the benthic communities, varies in relation to different environmental variables, i.e. depth, wave exposure at the seabed, and bottom salinity. The analysis was undertaken for the whole community and for two subsets of the benthic community responsible for filtering of the water column (suspension-feeders) and mixing of sediment (bioturbators). Using the relationships between the longevity-biomass composition and the environmental variables, we predicted a habitatspecific longevity composition for the whole community and the two functional groups across the Baltic Sea on a 0.05-0.05 degrees grid $\left(\sim 15 \mathrm{~km}^{2}\right.$, hereafter: grid cells). This prediction was derived in the absence of trawling and hypoxia (and anoxia) to estimate a reference state. We then calculated how both pressures have impacted the benthic community in all grid cells. Impact depends on the intensity of both pressures and the recovery rate, which decreases with longevity (Hiddink et al., 2017, 2019; Pitcher et al., 2017). We estimated the uncertainty of the model predictions and validated part of our model outputs using empirical data for Baltic Sea benthic communities over two gradients of commercial bottom trawling effort (for overview Figure 1).

\section{Benthic data across the Baltic Sea}

To estimate faunal longevity across the Baltic Sea, we used sampling data collated by Gogina et al. (2016). The dataset comprises $22685 \times 5 \mathrm{~km}$ cells (hereafter: locations) with information on species biomass in wet weight, including calcareous structures, without tubes (Figure 2). Each location contains one or multiple sampling events, taken in different years or at different periods in the year, which are aggregated to the $5 \times 5 \mathrm{~km}$ cell and expressed as the average biomass in $\mathrm{mg}$ per $\mathrm{m}^{2}$. As such, local variation in space and time in each location is ignored in this dataset, which means that our estimation of faunal longevity only captures large-scale spatial patterns. At all locations, benthic samples were

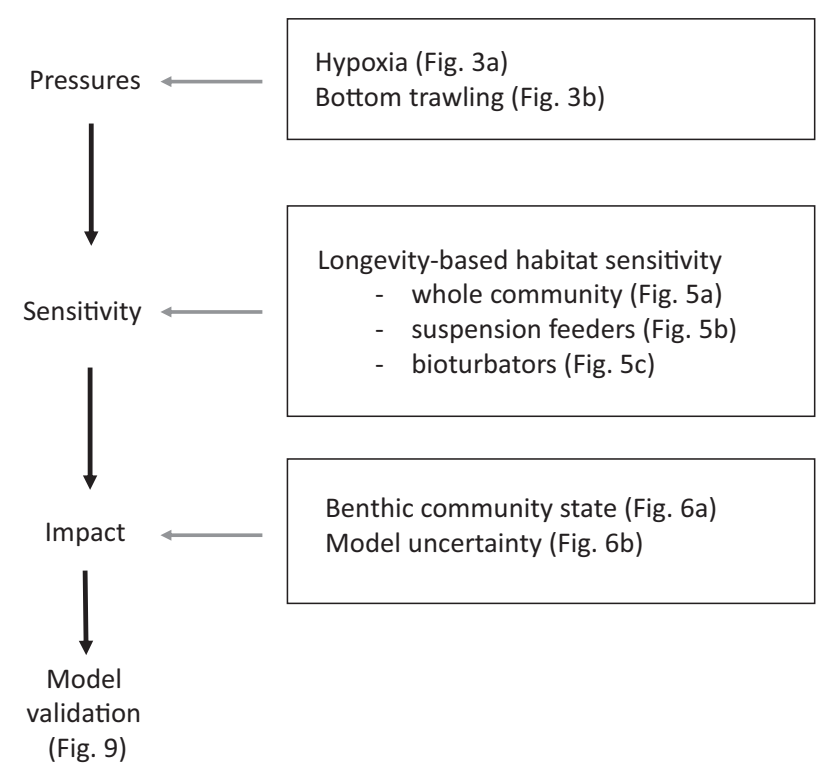

Figure 1. Outline of the method and results. 


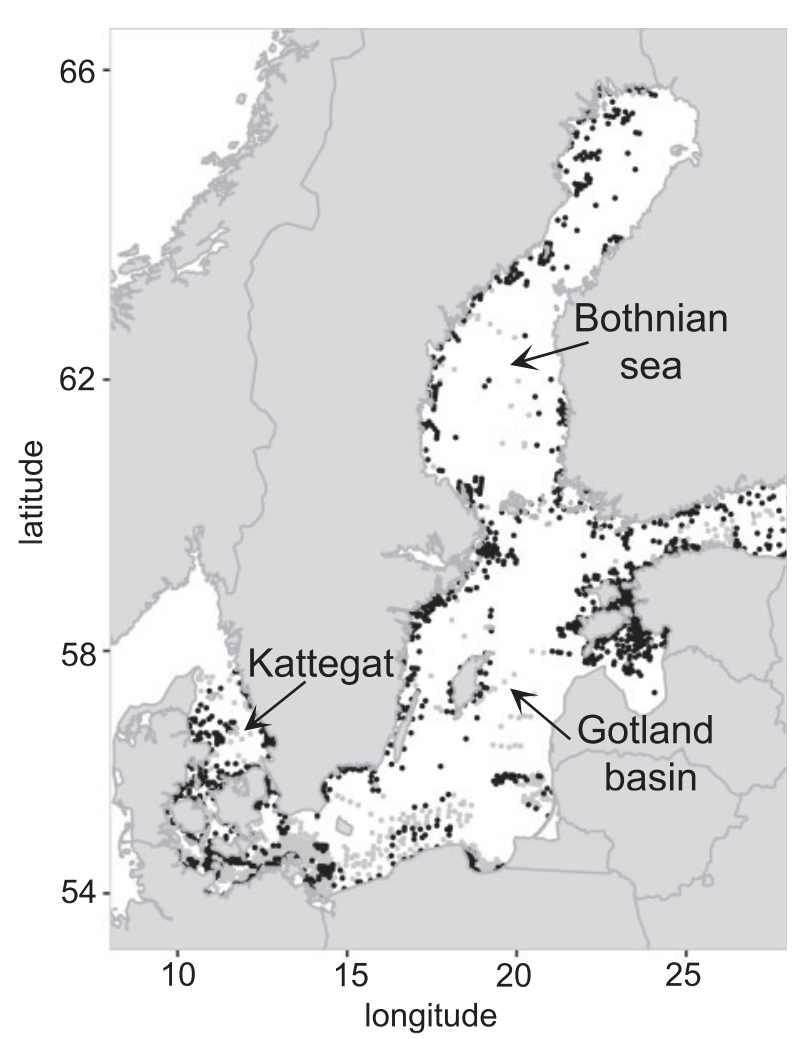

Figure 2. Sampling locations (based on aggregated benthic data) collated by Gogina et al. (2016). All black dots $(n=1558)$ were used in the analysis to predict fauna longevity. All grey dots $(n=710)$ were not used as pressure levels were too high.

collected with either box-cores or grab-samplers that both provide a quantitative estimate of the smaller epi- and infaunal part of the benthic community, for details on sampling, etc. see Gogina et al. (2016). Following Gogina et al. (2016), we assumed that the locations are quantitatively comparable across the Baltic Sea.

For each of the locations, benthic species were linked to a species-by-trait matrix with trait information on longevity (maximum lifespan). Benthic trait information was derived from available literature (Törnroos and Bonsdorff, 2012; Bolam et al., $2014,2017)$. Longevity was subdivided into four trait classes ( $<1$ year, $1-3,3-10$, and $>10$ years). For each species-longevity combination, a score of one was assigned to a single class when a species longevity matched a longevity class. Otherwise, fractional scores that summed to one were assigned to multiple longevity classes, following Bolam et al. (2014). From this species-by-longevity matrix, including in some cases higher taxonomic levels, a table of locations by biomass-weighted trait longevity classes was calculated by multiplying the total biomass per species by the longevity score. These were then summed by longevity class and divided by the total biomass of the location to produce a proportional biomass-weighted longevity table for all locations.

A biomass-weighted longevity table was also calculated for two functional groups of the benthic community that are responsible for key ecosystem processes. The first subset contains all suspension-feeders (e.g. Mya arenaria, Cerastoderma glaucum,
Phoronis sp.), which account for $60 \%$ of the total biomass in the dataset and filter the near-bed water, facilitating benthic-pelagic coupling processes. The second subset contains all bioturbators, which account for $35 \%$ of the total biomass in the dataset and mix the sediment, e.g. diffusive mixers and upward/downward conveyors (for terminology, see Bolam et al., 2017). When a taxon was only partly affiliated with the functional group, we proportionally allocated its biomass to the subset.

\section{Environmental variables}

To examine how the longevity-biomass composition varies across the Baltic Sea, we obtained different environmental variables. The Baltic Sea is a semi-enclosed sea with a large salinity gradient that strongly affects the composition of benthic communities (Bonsdorff, 2006). Bottom salinity data were obtained from the ICES data portal and interpolated to cover a Baltic-wide grid based on all data from 2005 to 2015. Depth was extracted from the Baltic Sea Hydrographic Commission (2013). Wave exposure at the seabed was derived following the principles of Bekkby et al. (2008) and was calculated for the whole Baltic Sea. No continuous sediment data were available for the entire Baltic Sea, and fractions mud, gravel, and sand were obtained for part of the region from the global dbSeabed database (Jenkins, 1997); no data were available in the northern Baltic Sea. Sediment fractions had little effect on the statistical model (not shown) and were left out of the analysis as the estimates are uncertain and limited in spatial extent. Wave exposure at the seabed and depth were both transformed to improve model fit as $\ln (x+1)$. The different habitat conditions were weakly correlated between each other. The correlation coefficient between wave exposure and depth is -0.46 , depth and salinity is -0.03 , and wave exposure and salinity is -0.06 .

\section{Oxygen deficiency and bottom trawling}

We obtained data on bottom oxygen concentrations and bottom trawling intensities for the Baltic Sea. Bottom oxygen concentrations $\left(\mathrm{ml} \mathrm{O}_{2} \mathrm{l}^{-1}\right)$ were extracted as seasonal means over 5 years (2006-2010) from an ecosystem model simulation (Figure 3a). This model setup, using the coupled hydrographical and biogeochemical system ERGOM-MOM (Schernewski et al., 2015), covers the whole Baltic Sea with a horizontal grid of 1-3 nautical miles. Trawling intensity was calculated based on average annual estimates of the amount of seabed disturbed by mobile bottomcontacting fishing gears (surface abrasion) on a 0.05·0.05 degrees grid between 2012 and 2016 (ICES, 2017). Bottom trawling intensity was expressed as the ratio between the area of a grid cell that is trawled each year (on average) and the total area of the grid cell (Figure 3b). There is a temporal mismatch between trawling intensity (2012-2016) and bottom oxygen concentrations (20062010) due to lack of bottom oxygen data covering the whole Baltic Sea in recent years.

\section{Longevity-biomass composition of the benthic community}

We estimated the longevity-biomass composition of the sampling locations across the Baltic Sea in relation to different environmental variables. The estimation was done using only sampling locations that are largely undisturbed by both pressures (but see Discussion), to derive a reference state. For trawling disturbance, Bolam et al. (2017) showed that it is possible to use both untrawled (i.e. a zero fishing pressure estimate) locations and locations with 

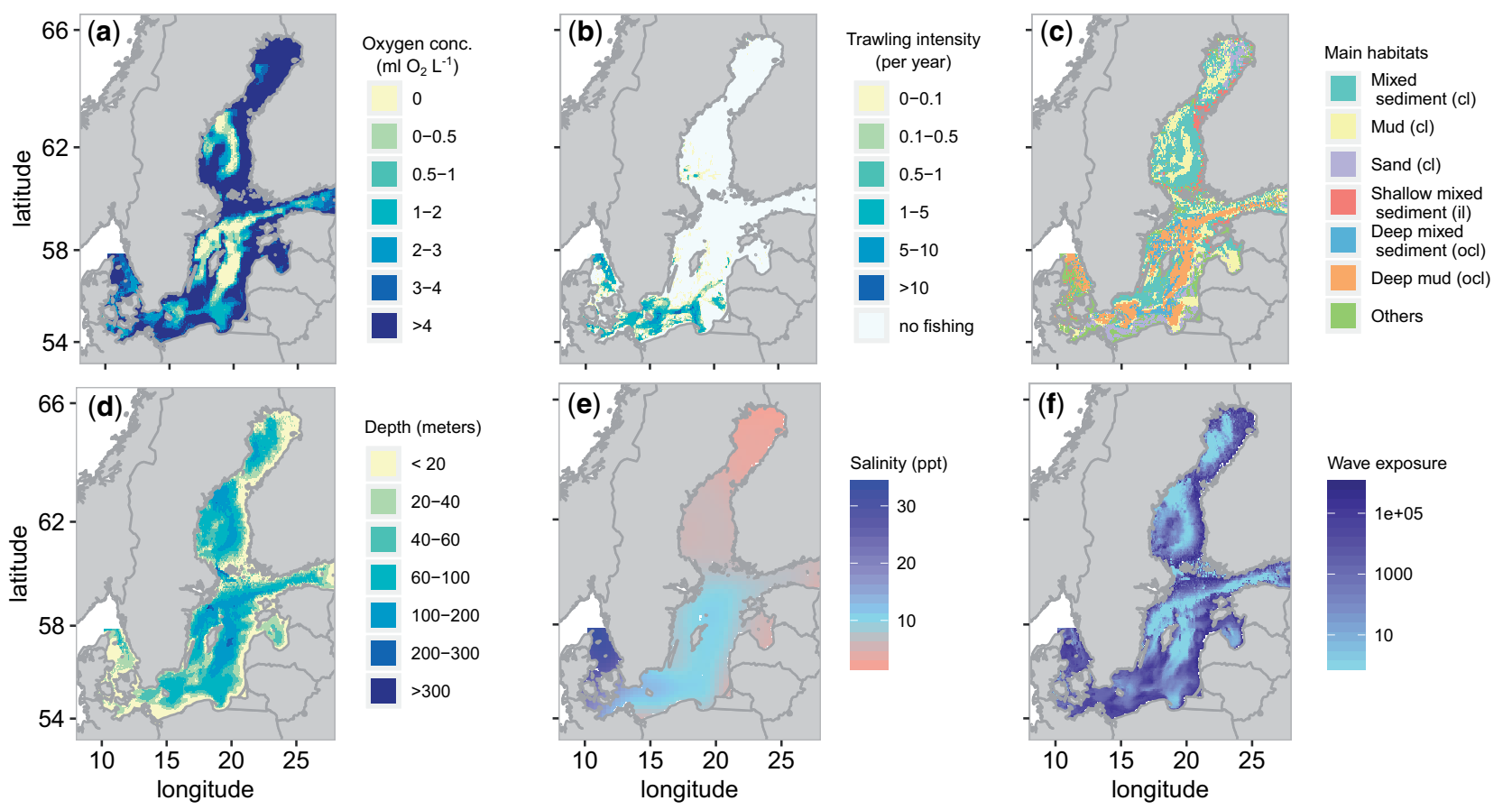

Figure 3. Map of (a) oxygen concentrations, here presented as the lowest seasonal concentration in the year, (b) trawling intensities, (c) the Marine Strategy Framework Directive Benthic Broad Habitat Types for the Baltic Sea region as downloaded from http://www. emodnet-seabedhabitats.eu/, (d) depth, (e) salinity, and (f) wave exposure at the seabed (unitless). See data sources and explanation in main text.

low trawling intensity (up to $\approx 0.1$ per year for the more sensitive habitats) to derive the reference state. For that reason, we used all sampling locations with average trawling intensities $<0.1$ per year. We used all sampling locations with minimum oxygen concentrations $>3.2 \mathrm{ml} \mathrm{O}_{2} \mathrm{l}^{-1}$, see below for rationale of the oxygen value. The relatively undisturbed locations $(n=1558)$ represent the range of habitat characteristics of the Baltic Sea, but with an overrepresentation of nearshore regions (Supplementary Appendix S1).

To statistically estimate the longevity composition in relation to environmental drivers, we converted the biomass by longevity to a cumulative biomass by calculating the biomass proportion with longevity that is smaller than or equal to 1,3 , and 10 years in each location. We assumed, following Rijnsdorp et al. (2018), that the shape of this cumulative biomass proportions-longevity relationship is a sigmoidal (logistic) function, which starts at 0 and approaches 1 when longevity becomes large (Figure 4). The cumulative proportions in each sample are not independent of each other. The dependence may have an effect on the standard error estimation but will not affect the estimated relationships between the longevity composition and the environmental drivers (which can therefore be used to predict the longevity-biomass composition for the Baltic Sea). We estimated the biomass-longevity composition using a statistical model, with the cumulative biomass proportions $(\mathrm{Cb})$ as the response variable and longevity (l) and environmental conditions $(\mathrm{Hab})$ as the predictor variables. We used a logistic mixed effect model with a random intercept per location (Rijnsdorp et al., 2018):

$$
C b \sim \beta_{0}+\beta_{1} \ln (l)+\beta_{2} H a b+\beta_{3} \ln (l) \cdot H a b+\varepsilon_{1}+\varepsilon_{2},
$$

where longevity $(l)$ is $\ln$ transformed, the first error term $\left(\varepsilon_{1}\right)$ has a binomial distribution and the second normally distributed error term $\left(\varepsilon_{2}\right)$ represents the random effect on the intercept per sampling location. The random effect had a variance component that was (very close to) zero in all analyses, but was retained in the model to incorporate the dependency of the cumulative biomass proportions per location.

We examined main effects and two-way interaction terms in all statistical procedures with model fits being evaluated using the Akaike Information Criterion (AIC). The best candidate model, i.e. lowest AIC, yet with a difference of $<2$ AIC units, the model with the fewest parameters was chosen, was used to extrapolate the longevity distribution and to calculate seabed sensitivity on a Baltic-wide scale (0.05-0.05 degrees grid) using the environmental conditions.

The longevity composition of the two different functional groups was estimated using a similar method as described above, except only these two functional groups were selected from the benthic community for each sampling location.

\section{Seabed state and impact}

For bottom trawling, Pitcher et al. (2017) derived a method to assess the relative state of the benthic community, the biomass relative to its carrying capacity, per grid cell by solving the logistic growth model:

$$
\text { Community state }=\frac{B}{K}=1-F \frac{d}{r} \text {, }
$$

where $B$ is the community biomass, $K$ is the carrying capacity, $r$ is the intrinsic growth rate per year of the benthic community, $F$ is the bottom trawling intensity per year, and $d$ is the proportional decline of benthic biomass caused by a single trawl pass.

The effects of oxygen deficiency on benthic communities substantially differ from those of trawling as oxygen concentrations 


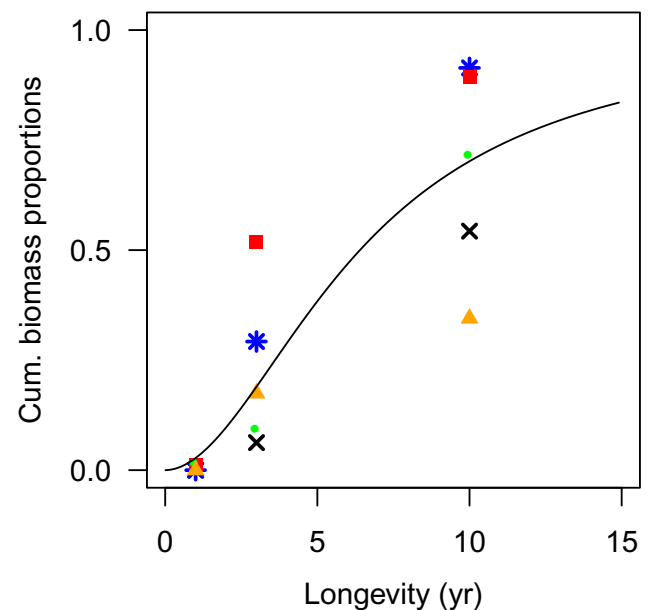

Figure 4. Illustration of five sampling stations with similar environmental conditions and their biomass-longevity compositions. Dots show cumulative biomass at longevities of 1,3 , and 10 based on benthic data (each station is a different symbol). Line is fitted (for illustration) with a binomial model where longevity is In transformed. Salinity $25-27 \mathrm{ppt}$, depth $10-13 \mathrm{~m}$, wave exposure $3 \cdot 10^{5}-5 \cdot 10^{5}$, fishing intensity $<0.1$ per year, and minimum seasonal oxygen concentration $>4 \mathrm{ml} \mathrm{O}_{2}$ per l.

have an effect that is dependent on both the severity and duration of oxygen deficiency (Vaquer-Sunyer and Duarte, 2008). For that reason, we formulated a temporal dynamic benthic model following van Denderen et al. (2015) to study the effects of both pressures:

$$
B(t+1)=B(t)+r_{\mathrm{d}} B(t)\left(\frac{K-B(t)}{K}\right)-\left(d f(t)+O_{\mathrm{def}}(t)\right) B(t),
$$

where $t$ is time in days, $f$ defines whether there is a trawling event $(f=1)$ or no event $(f=0)$ at a particular day, $d$ shows the decline of benthic biomass (as a fraction) caused by a single trawl pass [similar to Equation (2)], $r_{\mathrm{d}}$ the intrinsic growth rate per day, and $O_{\text {def }}$ describes mortality from oxygen deficiency at each day (detailed below). In the temporal model, trawling events were randomly distributed over the year based on the annual trawling frequency $F$ at each grid cell. The temporal model was run for 100 years through the 1-year period to derive an average state (see below).

The trawling mortality parameter $d$ is derived from a global meta-analysis (Hiddink et al., 2017), where $d$ is shown to be dependent on the penetration depth of the gear. Since essentially all bottom fishing vessels in the Baltic Sea use otter trawls (ICES, 2017), we use $d$ estimates derived in the meta-analysis for otter trawling $(d=0.06)$. An analysis of model uncertainty for parameter $d$ is described below (see Model uncertainty).

Similar syntheses of benthic community mortality from oxygen deficiency do not exist due to the difficulties of controlling for both the severity of oxygen deficiency and its duration. Studies of oxygen deficiency typically suggest that mass mortality occurs with seasonal concentrations around $0.5 \mathrm{ml} \mathrm{O}_{2} \mathrm{l}^{-1}$ (Diaz and Rosenberg, 1995). Oxygen concentrations above which species do not suffer any mortality are highly species dependent. Concentrations of $<1.4 \mathrm{ml} \mathrm{O}_{2} \mathrm{l}^{-1}$ are defined as hypoxic waters, but sensitive species experience lethal effects from oxygen deficiency at these concentrations (Vaquer-Sunyer and Duarte, 2008). Concentrations above $3.2 \mathrm{ml} \mathrm{O}_{2} \mathrm{l}^{-1}$ cause notably less mortality (Vaquer-Sunyer and Duarte, 2008) so a concentration of $3.2 \mathrm{ml} \mathrm{O}_{2} \mathrm{l}^{-1}$ was adopted as the seasonal oxygen concentration where the biomass of a healthy community is not declining.

We chose a function that defined mortality from oxygen deficiency $\left(O_{\mathrm{def}}\right)$ in such a way that a healthy community will experience (i) mass mortality in a season where oxygen concentrations are around $0.5 \mathrm{ml} \mathrm{O}_{2} \mathrm{l}^{-1}\left(\mathrm{O}_{\text {crit }}\right)$, (ii) little mortality in a season with oxygen concentrations $\geq 1.4 \mathrm{ml} \mathrm{O}_{2} \mathrm{l}^{-1}$, and (iii) no mortality in a season with oxygen concentrations $\geq 3.2 \mathrm{ml} \mathrm{O}_{2} \mathrm{l}^{-1}$. The above assumptions resulted in the following oxygen deficiency mortality function:

$$
O_{\text {def }}=d_{\mathrm{O}}\left(1+O_{\text {conc }}-O_{\text {crit }}\right)^{-6}
$$

where $O_{\text {conc }}$ is the daily concentration (where the daily concentration is the same for all days in a season; 92 days in winter and 91 days in the other seasons) and $d_{\mathrm{O}}$ a factor that scales the degree of daily mortality, parameterized as 0.01 (see Supplementary Appendix S2 for examples of seasonal mortality from oxygen deficiency). Similar to bottom trawling, mortality induced by oxygen deficiency affects all longevities equally. The exact parameterization of $O_{\text {crit }}$ and $d_{\mathrm{O}}$, in combination with the intrinsic growth rate $r$ of the community, will determine the benthic community state. An analysis of model uncertainty is described below (see Model uncertainty).

We used an intrinsic growth rate of the community $r$ that is independent of the type of disturbance, either from bottom trawling, oxygen deficiency, or both, because the mechanism of recovery, i.e. recruitment and growth following mortality, is assumed to be the same. Recovery rates are derived from field estimates of a global meta-analysis of recovery after trawling disturbance, where recovery is shown to be dependent on longevity (recovery rate per year $=r=H /$ longevity, with $H=5.31$, Hiddink et al., 2019). We used this formula to calculate the recovery rate and we divided $r$ in the temporal dynamic model by 365 to get an intrinsic growth rate per day $r_{\mathrm{d}}$. Uncertainty in $H$ and the predicted longevity distribution for the grid cells is evaluated (see Model uncertainty). The approach is based on a simple characterization of recovery; other important factors, such as larval strategy and mobility, are considered in the Discussion section.

We discretized the longevity distribution into 15 longevityclasses ( $1-14$ and $\geq 15$ ), and hence 15 recovery rates ( $r=H /$ longevity, with longevity from 1 to 15$)$, to run the temporal dynamic model in Equation (3). The model was run with $15 r_{\mathrm{d}}$ values and the final $B / K$ values, bounded between 0.001 and 1 , were multiplied with the 15 longevity-class biomass fractions and summed to estimate the community state. We ran the model for each grid cell that is affected by oxygen deficiency and/or bottom trawling for 100 years through the 1-year period, where trawling events each year are randomly distributed and oxygen deficiency follows a seasonal pattern. After the simulation, we calculated the average $B / K$ from the final 50 years to derive the average state of the benthic community.

\section{Model uncertainty}

We estimated model uncertainty for the depletion $d$ and recovery $H$ parameters and for the predicted biomass-longevity 
composition at each grid cell. The estimation of uncertainty was done by calculating benthic state 1500 times at each grid cell based on a resampling of the density distributions of the parameters. The value of $d$ had a logit-normal distribution with $\mu=\operatorname{logit}(0.06)$ and $\sigma=0.68$ (Hiddink et al., 2017), the value of $H$ a $\log$-normal distribution with mean $=\log (5.31)$ and $S D=$ 0.39 (Hiddink et al., 2019) and the biomass-longevity model estimates were assumed to be normally distributed. Uncertainty in benthic state was afterwards expressed as the difference between the 75 th and 25 th percentile. We also examined uncertainty in the oxygen deficiency parameters. Since these parameters are unquantified, we did not include them in the main uncertainty analysis, but tested oxygen deficiency separately in two scenarios where no fauna will occur on a location when oxygen concentrations in one season are either below 0.3 or $0.5 \mathrm{ml} \mathrm{O}_{2} \mathrm{l}^{-1}$, whereas all other grid cells are unaffected, i.e. on-off response.

\section{Model validation of bottom trawling}

We validated the impact assessment with empirical data of Baltic Sea benthic communities over two gradients of commercial bottom trawling effort in the Kattegat and Gotland Basin. In both areas, benthic sampling has been conducted in locations with relative constant environmental conditions and along a trawling gradient (see Supplementary Appendix S3 for further information). We first compared biomass proportions per longevity class for all undisturbed sampling stations (fishing intensity $<0.1$ year ${ }^{-1}$ ) with predicted proportions based on the model for the same locations. To allow a direct comparison, we used depth from the gradient studies as input parameter in the model, whereas salinity and wave exposure at the seabed were taken from the Baltic-wide dataset. Afterwards, we examined the effects of fishing on total community biomass in the gradient studies and compared the empirical outcomes with the predicted impact from the model. We did not validate the effects of hypoxia (see Discussion).

\section{Data accessibility}

Output and code of the assessment model and benthic trait information are available on Github with doi: http://doi.org/10.5281/ zenodo. 3346899 .

\section{Results}

\section{Longevity composition of the benthic community}

Table 1 shows an overview of the statistical models that fitted the data best for both the total benthic community and the specific functional groups. The cumulative biomass proportions across longevity of the overall benthic community are best described by salinity, longevity, and depth and their interactions (with a greater longevity in deep and high-salinity areas), while wave stress at the seabed has a negative effect. Using the statistical model outcome, the longevity composition of the benthic community is predicted across the Baltic Sea (Figure 5a) based on the underlying environmental conditions (Figure $3 \mathrm{~d}-\mathrm{f}$ ). The prediction shows a large spatial variation in the longevity composition that is largely driven by salinity and the interactive effects between salinity and depth. Low salinity and depth correlate with communities whose biomass is dominated by short-lived taxa, e.g. Monoporeia affinis (amphipod), Marenzelleria spp. (polychaete), and Saduria entomon (isopod), whereas those of the relatively high-salinity Kattegat are dominated by long-lived species such as Amphiura spp. (brittle stars) and Arctica islandica (bivalve).

The best candidate model for the longevity composition of suspension-feeders is similar to the statistical model for the whole benthic community (Table 1) and results in a similar spatial pattern with somewhat longer-lived fauna (Figure 5b). The best candidate model for bioturbators does not include an interaction between longevity and salinity (Table 1). The median longevity of bioturbators is lower than that for suspension-feeders in areas with high salinity, while in the remaining parts of the Baltic Sea median longevities are generally comparable (Figure $5 c$ ).

\section{Predicting the state of the benthic community}

For all three faunal groups, the low salinity in most regions of the Baltic Sea correlates with a longevity distribution of mostly shortlived species. These communities are, in our model, predicted to be more resilient to the effects of both pressures than the high-salinity communities in the Kattegat. The predicted state of the benthic community in response to both pressures is shown in Figure 6a. In $22 \%$ of the Baltic Sea, the state of benthic habitats is below 0.90 (a state of 1 is unimpacted) and the state is below 0.50 in $14 \%$ of the Baltic Sea (Figure 7). Impact is summarized in Table 2 per main

Table 1. Model selection for the cumulative biomass proportions in relation to longevity and habitat conditions for the total community and different functional groups.

\begin{tabular}{|c|c|c|c|}
\hline Model & df & AIC & Formula \\
\hline \multicolumn{4}{|l|}{ Total community $(n=1558)$} \\
\hline$L+S+D+W+L \cdot S+S \cdot D+L \cdot D$ & 9 & 2525 & $\mathrm{Y}=-4.2+3.7 \mathrm{~L}+0.1 \mathrm{~S}+0.2 \mathrm{D}-0.1 \mathrm{~W}-0.1 \mathrm{~L} \cdot \mathrm{S}-0.04 \mathrm{~S} \cdot \mathrm{D}+0.3 \mathrm{~L} \cdot \mathrm{D}$ \\
\hline$L+S+D+W+L \cdot S+L \cdot D$ & 8 & 2530 & - \\
\hline $\mathrm{L}+\mathrm{S}+\mathrm{D}+\mathrm{L} \cdot \mathrm{S}+\mathrm{S} \cdot \mathrm{D}+\mathrm{L} \cdot \mathrm{D}$ & 8 & 2560 & - \\
\hline $\mathrm{L}+\mathrm{S}+\mathrm{D}+\mathrm{W}$ & 6 & 2600 & - \\
\hline \multicolumn{4}{|l|}{ Suspension-feeders ( $n=1487)$} \\
\hline $\mathrm{L}+\mathrm{S}+\mathrm{D}+\mathrm{W}+\mathrm{L} \cdot \mathrm{S}+\mathrm{S} \cdot \mathrm{D}+\mathrm{L} \cdot \mathrm{D}$ & 9 & 2457 & $Y=-4.5+3.3 \mathrm{~L}+0.2 \mathrm{~S}-0.1 \mathrm{D}-0.1 \mathrm{~W}-0.1 \mathrm{~L} \cdot \mathrm{S}-0.05 \mathrm{~S} \cdot \mathrm{D}+0.5 \mathrm{~L} \cdot \mathrm{D}$ \\
\hline $\mathrm{L}+\mathrm{S}+\mathrm{D}+\mathrm{W}+\mathrm{L} \cdot \mathrm{S}+\mathrm{L} \cdot \mathrm{D}$ & 8 & 2503 & - \\
\hline$L+S+D+L: S+S \cdot D+L \cdot D$ & 8 & 2474 & - \\
\hline $\mathrm{L}+\mathrm{S}+\mathrm{D}+\mathrm{W}$ & 6 & 2598 & - \\
\hline \multicolumn{4}{|l|}{ Bioturbators $(n=1536)$} \\
\hline$L+S+D+W+S \cdot D+L \cdot D$ & 8 & 2577 & $\mathrm{Y}=-1.9+2.1 \mathrm{~L}+0.001 \mathrm{~S}-0.3 \mathrm{D}-0.18 \mathrm{~W}-0.03 \mathrm{~S} \cdot \mathrm{D}+0.5 \mathrm{~L} \cdot \mathrm{D}$ \\
\hline $\mathrm{L}+\mathrm{S}+\mathrm{D}+\mathrm{W}+\mathrm{L} \cdot \mathrm{D}$ & 7 & 2589 & - \\
\hline$L+S+D+W+L \cdot S+L \cdot D$ & 8 & 2590 & - \\
\hline $\mathrm{L}+\mathrm{S}+\mathrm{D}+\mathrm{W}$ & 6 & 2617 & \\
\hline
\end{tabular}

L, In(longevity); S, salinity; $D, \ln ($ depth +1$) ; W, \ln ($ wave exposure at the bottom +1 ). 

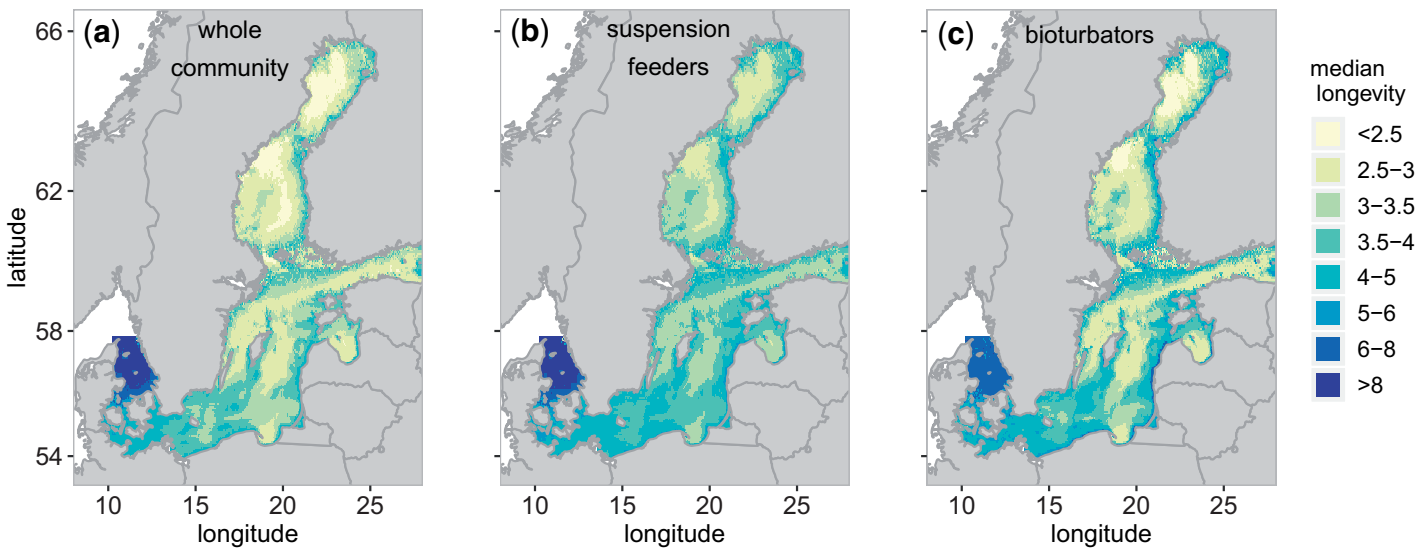

Figure 5. Predicted longevity distribution of the (a) benthic community, (b) suspension-feeders, and (c) sediment bioturbators across the Baltic Sea, presented as the median longevity, the longevity in years where the cumulative biomass proportion is 0.5 .
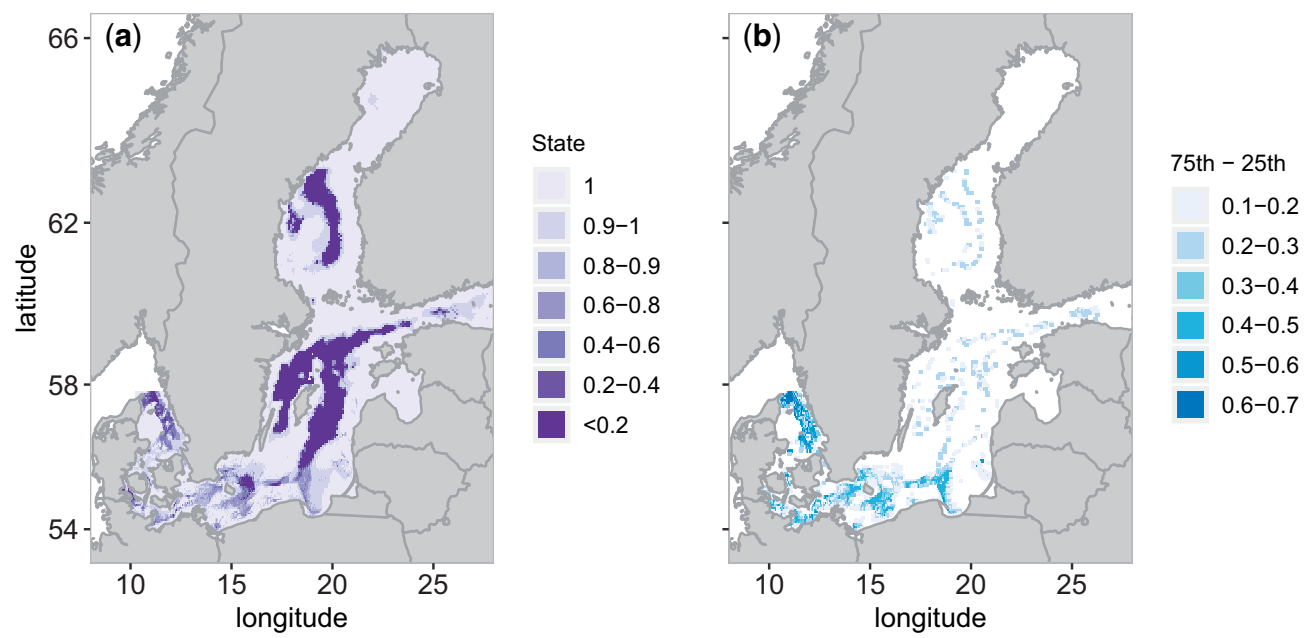

Figure 6. (a) Predicted state of the benthic community impacted by fishing disturbance and oxygen deficiency (a state of 1 is unimpacted) and (b) model uncertainty measured as the difference in state between 25th and 75th percentile based on uncertainty in the depletion $d$ and recovery $\mathrm{H}$ parameters and the statistical model predictions of the biomass-longevity composition at each grid cell.

habitat type (see Figure $3 c$ for a map of the main habitats). This shows that deep mud is most affected, with on average a community state of 0.42 . Deep mud is spatially extensive and covers $16 \%$ of the seabed, predominantly in the middle part of the Baltic Sea where oxygen deficiency is greater. Another relatively deep benthic habitat, deep mixed sediment that covers $6 \%$ of the Baltic Sea, also displays a low community state (state $=0.48$ ). Mixed sediment, the most spatially dominant habitat, has a relatively unimpacted state of 0.94 , whereas shallow mud has a state of 0.84 . Suspension-feeders and bioturbators have a similar state as the whole community in all habitat types (Table 2).

Results of the uncertainty analysis show that the predicted impacts are most uncertain in areas with a high predicted faunal longevity and high bottom fishing intensity, i.e. Kattegat (Figure 6b). The uncertainty in oxygen deficiency is low in the middle part of the Baltic Sea and hence limitedly affected by uncertainty in faunal longevity or parameter $H$. The impact of oxygen deficiency mainly depends on the oxygen concentrations that cause mass mortality (Supplementary Appendix S4).
The community state of the main habitats varies maximally \pm 0.1 from the main result based on the 25th and 75th percentile (Supplementary Appendix S4).

In $6 \%$ of the Baltic Sea region benthic biomass is reduced by at least $10 \%$ due to the combined impact of bottom trawling and oxygen deficiency. The average state of these areas is 0.59 (Table 3). In our model specification, we have assumed that the effects of bottom trawling and oxygen deficiency on benthic ecosystems are additive, resulting in a combined impact as illustrated in Figure 8. The combined impact always results in a lower benthic state than the effect of a single pressure. Changes in impact are nonlinear because low oxygen concentrations, or high bottom trawling intensities, shift the community to a younger mean age by disproportionally removing long-living biota.

\section{Model validation}

The longevity composition of the benthic community differs markedly between the Kattegat and Gotland Basin (Figure 9a and b). Most organisms in the Gotland Basin have longevities of 3-10 years, 


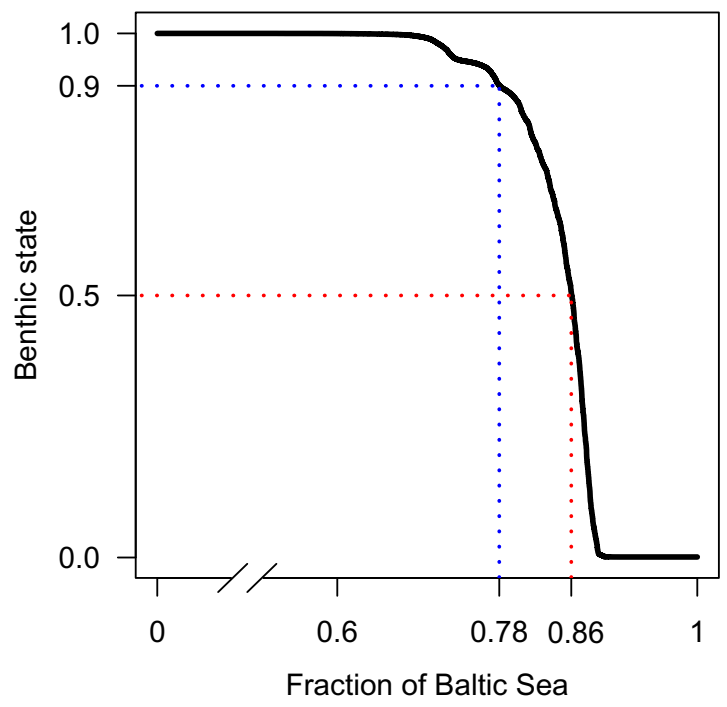

Figure 7. The benthic state per grid cell sorted from high to low and the corresponding fraction of the Baltic Sea area above or equal to that state. The figure shows that $22 \%(1-0.78=0.22)$ of the Baltic Sea region has a state $<0.9$ and $14 \%(1-0.86=0.14)$ has a state $<0.5$.

Table 2. Overview of impact (presented as the average grid cell state) by both pressures for the total community and for different functional groups in the most common habitat types.

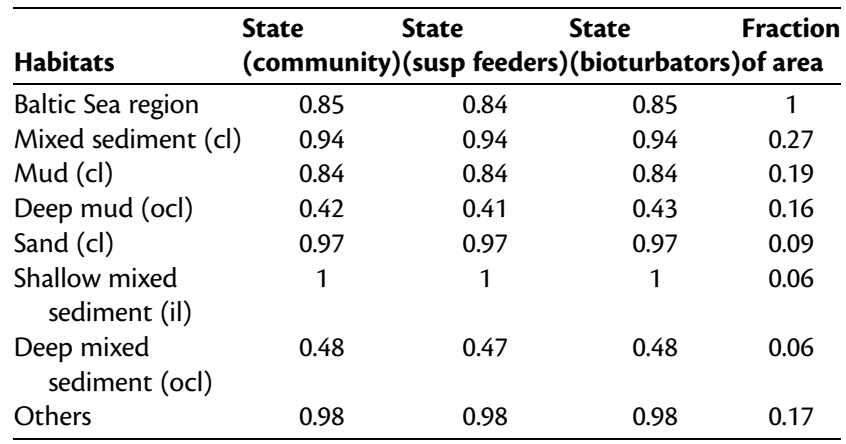

Fraction of area is the surface area of a habitat type divided by the total assessed area.

cl, circalittoral; il, infralittoral; ocl, offshore circalittoral.

whereas longer-lived ( $>10$ years) organisms are predominant in the Kattegat. These distributions of longevity are also predicted with the model, despite an underestimation of the proportion of long-lived organisms in the Kattegat (Figure 9a and b). Both the model and the data show a decline in community biomass in the Gotland Basin with increased trawling, although the decline is stronger in the data (Figure 9c). There is no clear biomass change, and large variability, in the Kattegat in response to trawling, whereas the model predicts a reduction (Figure 9d). The large variability in biomass is not captured in the model as we assumed a carrying capacity $K$ that is calculated as the average community biomass of all undisturbed stations.

\section{Discussion}

Our results show that the low salinity in most regions of the Baltic Sea correlates with a community biomass-longevity distribution that is heavily biased towards short-lived species. In our
Table 3. Overview of the average state and areal extent of grid cells where benthic biomass is reduced by at least $10 \%$ (state $<0.90$ ) due to bottom trawling, oxygen deficiency, or both.

\begin{tabular}{lll}
\hline Pressure & $\begin{array}{l}\text { Average } \\
\text { state }\end{array}$ & $\begin{array}{l}\text { Fraction of the } \\
\text { total Baltic Sea region }\end{array}$ \\
\hline Bottom trawling $(F>0.1, O \geq 3.2)$ & 0.71 & 0.03 \\
Oxygen deficiency $(F \leq 0.1, O<3.2)$ & 0.11 & 0.13 \\
Both $(F>0.1, O<3.2)$ & 0.59 & 0.06 \\
\hline
\end{tabular}

The total area of the Baltic Sea with a state $<0.9$ is $22 \%$ (see Figure 7 ). $F$ is the bottom trawling intensity, $O$ is the minimum seasonal oxygen concentration in $\mathrm{mlO}_{2} \mathrm{I}^{-1}$.

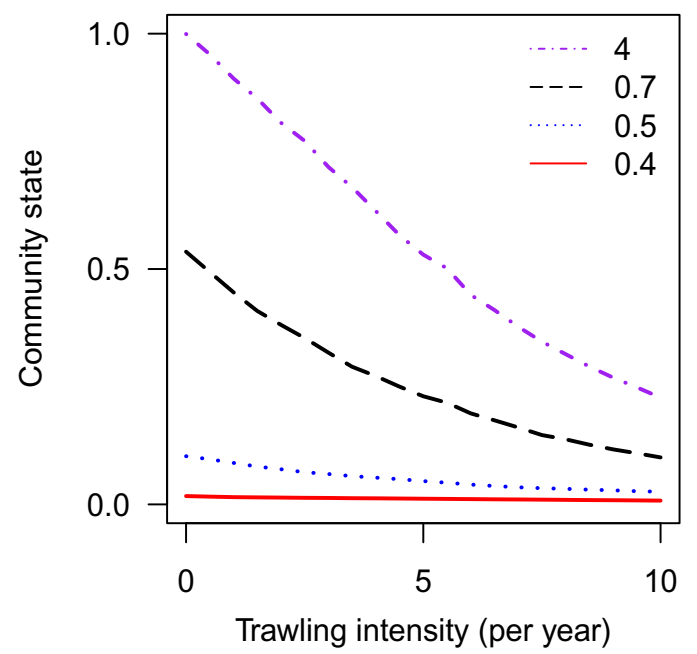

Figure 8. Illustration of the combined effects of bottom trawling and oxygen deficiency on benthic community state. The lines show different summer oxygen concentrations, whereas the oxygen concentrations in the other seasons are $4 \mathrm{ml} \mathrm{O}_{2}$ per l; note that similar results are obtained when oxygen concentrations are low in another season. The longevity composition of the benthic community, used to predict impact and state, is estimated from the statistical model (Table 1) based on chosen environmental conditions (salinity $26 \mathrm{ppt}$, depth $12 \mathrm{~m}$, wave exposure at the bottom $3 \cdot 10^{5}$, representing a location in the Kattegat). The combined effects are largely similar for other regions, but the nonlinear effect becomes smaller in areas with short-lived fauna.

model, these communities are more resilient to the effects of hypoxia and bottom trawling than those of the highly saline areas where biomass comprised relatively long-lived species. We find that in $14 \%$ of the Baltic Sea region benthic biomass is reduced by at least $50 \%$ (state $<0.5$ ), whereas $8 \%$ of the region has reductions of $10-50 \%$. About one quarter of these impacted areas is affected by both pressures, corresponding to $6 \%$ of the Baltic Sea region with cumulative impacts. The effects of hypoxia cover larger areas and lead to a low habitat state of deep mud and deep mixed sediment.

\section{Longevity distribution of the Baltic Sea benthic community}

For the estimated reference conditions, the longevity-biomass distribution of the benthic community differed substantially between habitats. Changes in longevity are primarily driven by the salinity gradient from the Kattegat towards the Gotland Basin 
(a)

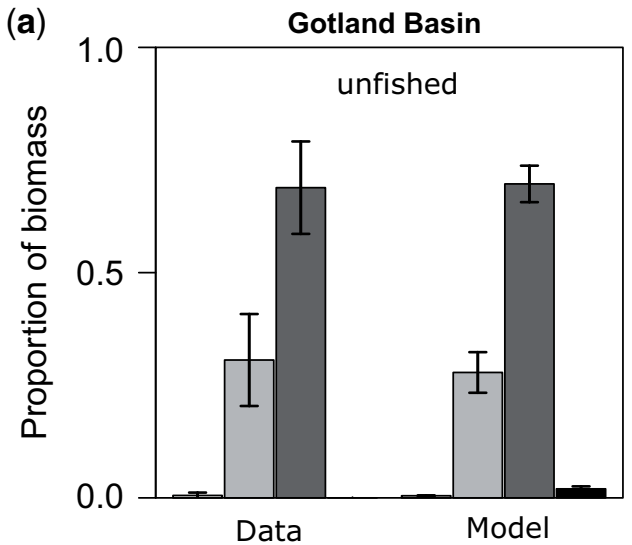

(c)

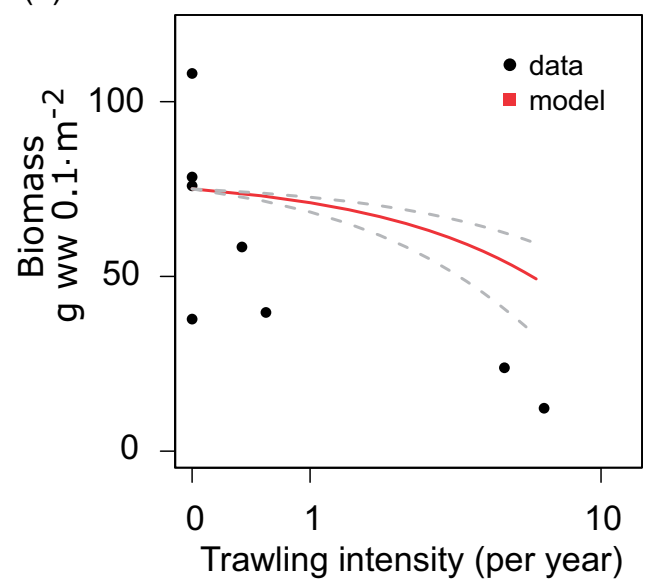

(b)

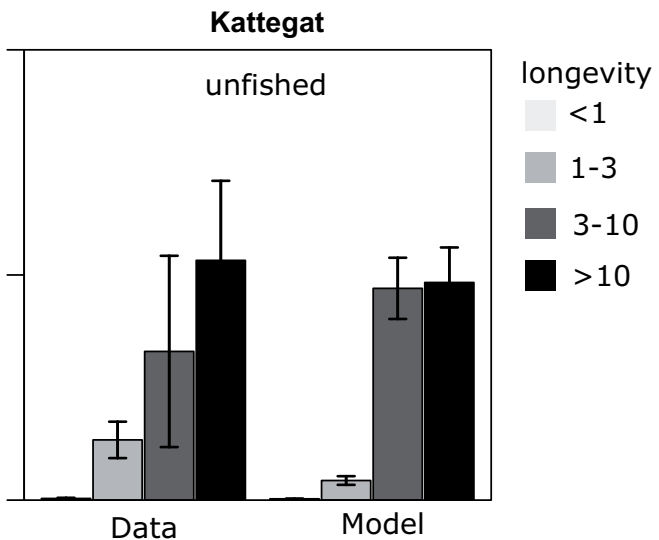

(d)

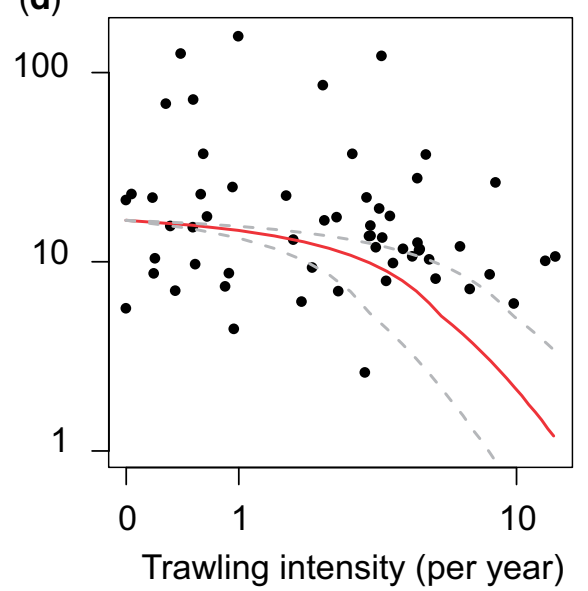

Figure 9. Model predictions of longevity are compared to data observations at four unfished stations in the Gotland Basin (a) and three unfished stations in the Kattegat (b). The bars show the average biomass proportion per longevity class and the error bars show the standard error. Model predictions of fishing impact are compared to data in panels $\mathrm{c}$ and $\mathrm{d}$. The black dots show the observed community biomass at each sampling station and the solid lines show the predicted biomass as a function of trawling intensity. Changes in biomass in response to trawling intensity are derived in the model by calculating impact from the predicted longevity composition in panels a and $b$, from fishing intensity and by assuming a carrying capacity $(K)$ that is the average community biomass in all undisturbed stations. Model uncertainty (grey dashed lines) is estimated by resampling the depletion rate from trawling $d$ and the longevity-specific recovery rate $H 1500$ times. Other sources of uncertainty are not included. The benthic data and fishing intensities for each sampling station are averaged for all years of sampling. Panel $d$ shows the $y$-axis on a $\log _{10}$ scale.

and the Bothnian Sea, which has been shown to strongly influence the benthic community (Bonsdorff, 2006; Törnroos et al., 2015). In the high-salinity waters of the Kattegat, the longevity distribution is comparable to that predicted for the neighbouring North Sea (Rijnsdorp et al., 2018), and in both regions suspension-feeders consist of a higher fraction of longer-lived species than the bioturbators. The longevity of all groups declines notably in the low-salinity waters of the Baltic Sea.

The longevity distribution of the benthic community is used in this study as a proxy of benthic sensitivity to trawling and oxygen deficiency. The use of this proxy is based on the findings by Hiddink et al. (2019) who showed that the intrinsic rate of population growth $r$, which drives the recovery rate, is proportional to the reciprocal of longevity. It is also supported by other studies that show shifts towards shorter-lived species in response to trawling (Tillin et al., 2006; van Denderen et al., 2015; Rijnsdorp et al., 2018) and hypoxia (Diaz and Rosenberg, 1995). Although longevity is a key trait that correlates with habitat sensitivity and recovery, estimating the longevity of benthic taxa is uncertain because benthic taxa cannot be aged and other factors, besides longevity, affect benthic sensitivity. Large variations in recovery rates within longevity classes were observed in the meta-analysis of Hiddink et al. (2019), highlighting uncertainty in using longevity to estimate benthic recovery. Uncertainty is also shown in our model validation analysis, where the model underestimates the effect of fishing in the Gotland Basin, where short-lived fauna dominate, and overestimates the fishing effect on long-lived organisms in the Kattegat (Figure 9). For the Kattegat, long-lived organisms seem to be largely insensitive to trawling, which is contradictory to the meta-analysis by Hiddink et al. (2019). The limited effect of fishing on long-lived organisms in the Kattegat is most likely due to an increase in the long-living and abundant brittle stars (Amphiura spp.) under intermediate trawling disturbance (Sköld et al., 2018). Hence, further work is needed to elucidate when responses of the benthic community are not (solely) dependent on the longevity of fauna. Studying the response of biological-trait groupings to various pressures (Villnäs et al., 2018) or incorporating the food-web dynamics and the possibility 
of having nonlinear and non-negative responses to pressures, see for example for trawling van Denderen et al. (2013) and Sköld et al. (2018), offer two potential approaches in this respect. Nevertheless, from our model validation we are unable to determine whether the response of Baltic Sea benthic communities systematically differs from the results of the global meta-analysis (Hiddink et al., 2019), i.e. the recovery rate is proportional to the reciprocal of longevity.

The longevity composition of the benthic community was derived using only sampling locations that were assumed to be largely undisturbed by the pressures. It is likely that most undisturbed sampling locations are not in "pristine" condition, e.g. sampling locations might have been at a state of recovery from historic fishing, hypoxia or are impacted by other pressures. The sampling locations used to predict the longevity are also predominantly shallow, limiting the accuracy of our longevity prediction in deeper areas. In our estimation of the reference condition, we also did not include that a minor part of the Baltic Sea seafloor is naturally, and historically, disturbed by hypoxia (Carstensen et al., 2014). Furthermore, our predictions are uncertain by a lack of continuous sediment data, as sediment conditions will likely affect faunal longevity. The reference state is hence based on the best condition currently available and may be updated when new information becomes available.

\section{The effects of bottom trawling and hypoxia}

Our results show that $6 \%$ of the Baltic Sea region $\left(\sim 30000 \mathrm{~km}^{2}\right)$ is currently impacted by both bottom trawling and oxygen deficiency. We have assumed that the effects of bottom trawling and oxygen deficiency on benthic ecosystems are additive and both shift the community to a younger mean age. Evidence also suggests potential synergistic effects through other mechanisms, as oxygen deficiency can induce burrowing organisms to migrate to the sediment surface (Baden et al., 1990; Hansson et al., 2000) making them potentially more vulnerable to trawling impacts. To date, however, no targeted study has been conducted to determine the nature of any cumulative impacts of these two pressures. Synergistic effects, if shown to occur, could be included in the assessment model and are likely to result in a reduced benthic habitat state in areas with both pressures, compared to our model predictions. Understanding the interactive effects is important as hypoxic conditions are predicted to expand in the Baltic Sea (Bendtsen and Hansen, 2013) and in coastal areas in general (Breitburg et al., 2018) with climate warming, potentially increasing the area that is affected by both pressures.

\section{Model parametrization}

The effects of oxygen deficiency in the model are largely based on the assumption of mass mortality at $0.5 \mathrm{ml} \mathrm{O}_{2} \mathrm{l}^{-1}$ and changes in this parameter affect the average state of especially deep offshore habitats (Supplementary Appendix S4). Part of these deep offshore habitats has oxygen concentrations close to or even zero and these areas are, even in a best-possible scenario, highly impacted. The response of benthic communities at higher oxygen concentrations $\left(>1 \mathrm{ml} \mathrm{O}_{2} \mathrm{l}^{-1}\right)$ is assumed to cause little mortality to the benthic community (Supplementary Appendix S2). A proper validation of these model results across regions and benthic communities is needed, both in relation to the concentration and duration of oxygen deficiency. The oxygen concentrations used to predict impact are now also based on seasonal averages, whereas a few hours/days of anoxic conditions may already result in mass mortality (Villnäs et al., 2012). A finer temporal resolution of the simulated bottom oxygen conditions, in combination with an improved parametrization of oxygen deficiency, will refine our modelling results.

The intrinsic growth rate of the community $r$, which drives the recovery rate, is independent of the type of disturbance in our model. Recovery rates are likely to differ between trawling and hypoxia as the physical and physico-chemical conditions and the spatial scale of these disturbances differ. Trawling is patchy in space and time (Rijnsdorp et al., 1998; van Denderen et al., 2015) which enhances the potential for local, less disturbed communities to facilitate recolonization through larval dispersal and postsettlement movement. In contrast, the relatively continuous and spatially extensive nature of severely hypoxic areas hinders such recolonization processes (Whitlatch et al., 1998). The severe hypoxic areas are also characterized by mud and mud may harbour a specific benthic community, further limiting successful recolonization from neighbouring (non-muddy) habitats. Our models may, therefore, be improved by allowing recovery rates to be dependent on the community (dis)continuity, or degree of patchiness. In addition, larval dispersal mechanisms by the benthos are limited due to the lack of tidal currents in the Baltic Sea (Valanko et al., 2010) and recovery rates may potentially differ from those of other regions.

\section{Conclusion}

We have applied a method for assessing the combined effects of trawling disturbance and hypoxia on benthic communities. The approach is based on a simple characterization of the benthic community. With the exception of the estimation of faunal longevity, the parameterization of depletion and recovery rates are derived from meta-analyses outside the Baltic Sea. The approach comes as such with high uncertainty. The approach has been used to identify regions that are most at risk, so as to prioritize management actions. The approach can be used to monitor changes over time by evaluating benthic state with temporal pressure data. The assessment methodology can be transferred to other regions where the benthic longevity-biomass composition can be estimated and where high-resolution pressure data are available. The method allows to aggregate results from a local scale $\left(\sim 15 \mathrm{~km}^{2}\right)$ to the main habitats (and potentially any other assessment unit), as well as to the regional scale (Baltic Sea; $\sim 450000$ $\mathrm{km}^{2}$ ). We expect our findings and the assessment method to be of relevance to managers as it objectively highlights how bottom trawling and oxygen deficiency act on benthic habitats. Within a regional policy context, such an assessment method is required to evaluate benthic seafloor integrity and how changes may be occurring over time. Information on benthic seafloor integrity will facilitate the development of sustainable management strategies and assist in the assessment of trade-offs between human activities and their environmental impact on the seabed.

\section{Supplementary data}

Supplementary material is available at the ICESJMS online version of the manuscript.

\section{Acknowledgements}

We thank three reviewers for their valuable comments that have improved the manuscript. We thank F. Bastardie and P. Jonsson for trawling intensities for the Gotland data, K. Cooper for 
commenting the manuscript and C. Jenkins for making the dbSeabed database available. Maps of seabed habitats have been derived from data that is made available under the European Marine Observation Data Network (EMODnet) Seabed Habitats project (http://www.emodnet-seabedhabitats.eu/), funded by the European Commission's Directorate-General for Maritime Affairs and Fisheries (DG MARE).

\section{Funding}

P.D.v.D., M.S., K.N., and S.V. were partly supported by BalticBOOST a HELCOM project co-financed by the EU (No. 11.0661/2015/712632/SUB/ENVC.2). M.S. and K.R. were also cofinanced by the Swedish Agency for Marine and Water Management (Dnr 74915). Data used in this article along local trawling gradients were collected within Swedish National and monitoring programmes and financed by the Swedish Agency for Marine and Water Management, SwAM. J.G.H. and A.R. were partly supported by BENTHIS EU-FP7 312088; the paper has benefitted from discussions within BENTHIS and Trawling Best Practice groups. E.A.V. was partly supported by the Academy of Finland Strategic Research Council (project SmartSea, Grant No. 314225). A.T. was supported by the Åbo Akademi University profiling area "The Sea" and the BIO-C3 project, which received funding from BONUS, the joint Baltic Sea research and development programme (Art 185) and national funding agencies. P.D.v.D. conducted the work within the Centre for Ocean Life, a VKR Centre of excellence supported by the Villum Foundation.

\section{Author contributions}

P.D.v.D., J.G.H., A.D.R., M.S., A.T., and S.V. conceived the ideas. A.T. and S.G.B. collated benthic trait data. R.F. and E.A.V. derived environmental modelled data. K.N. and M.S. collated benthic validation data. P.D.v.D. performed the analyses with support of J.G.H., A.D.R., K.N., and M.S. P.D.v.D. and S.V. led the writing and all authors contributed critically to the drafts.

\section{References}

Amoroso, R. O., Pitcher, C. R., Rijnsdorp, A. D., McConnaughey, R. A., Parma, A. M., Suuronen, P., Eigaard, O. R. et al. 2018. Bottom trawl fishing footprints on the world's continental shelves. Proceedings of the National Academy of Sciences, 115: E10275-10282.

Baden, S. P., Loo, L.-O., Pihl, L., and Rosenberg, R. 1990. Effects of eutrophication on benthic communities including fish: Swedish west coast. AMBIO: A Journal of the Human Environment, 19: 113-122.

Baltic Sea Hydrographic Commission. 2013. Baltic Sea Bathymetry Database Version 0.9.3. http://data.bshc.pro/ (last accessed 21 February 2017).

Bekkby, T., Isachsen, P. E., Isæus, M., and Bakkestuen, V. 2008. GIS modeling of wave exposure at the seabed: a depth-attenuated wave exposure model. Marine Geodesy, 31: 117-127.

Bendtsen, J., and Hansen, J. L. S. 2013. Effects of global warming on hypoxia in the Baltic Sea-North Sea transition zone. Ecological Modelling, 264: 17-26.

Bolam, S. G., Coggan, R. C., Eggleton, J., Diesing, M., and Stephens, D. 2014. Sensitivity of macrobenthic secondary production to trawling in the English sector of the Greater North Sea: a biological trait approach. Journal of Sea Research, 85: 162-177.

Bolam, S. G., Garcia, C., Eggleton, J., Kenny, A. J., Buhl-Mortensen, L., Gonzalez-Mirelis, G., van Kooten, T. et al. 2017. Differences in biological traits composition of benthic assemblages between unimpacted habitats. Marine Environmental Research, 126: 1-13.
Bonsdorff, E. 2006. Zoobenthic diversity-gradients in the Baltic Sea: continuous post-glacial succession in a stressed ecosystem. Journal of Experimental Marine Biology and Ecology, 330: 383-391.

Breitburg, D., Levin, L. A., Oschlies, A., Grégoire, M., Chavez, F. P., Conley, D. J., Garçon, V. et al. 2018. Declining oxygen in the global ocean and coastal waters. Science, 359: eaam7240.

Carstensen, J., Andersen, J. H., Gustafsson, B. G., and Conley, D. J. 2014. Deoxygenation of the Baltic Sea during the last century. Proceedings of the National Academy of Sciences, 111: $5628-5633$.

Collie, J. S., Hall, S. J., Kaiser, M. J., and Poiner, I. R. 2000. A quantitative analysis of fishing impacts on shelf-sea benthos. Journal of Animal Ecology, 69: 785-798.

Conley, D. J., Bjorck, S., Bonsdorff, E., Carstensen, J., Destouni, G., Gustafsson, B. G., Hietanen, S. et al. 2009. Hypoxia-related processes in the Baltic Sea. Environmental Science \& Technology, 43: 3412-3420.

de Groot, S. J. 1984. The impact of bottom trawling on benthic fauna of the North Sea. Ocean Management, 9: 177-190.

Diaz, R. J., and Rosenberg, R. 1995. Marine benthic hypoxia: a review of its ecological effects and the behavioural responses of benthic macrofauna. Oceanography and Marine Biology: An Annual Review, 33: 203-245.

Diaz, R. J., and Rosenberg, R. 2008. Spreading dead zones and consequences for marine ecosystems. Science, 321: 926-929.

Eigaard, O. R., Bastardie, F., Breen, M., Dinesen, G. E., Hintzen, N. T., Laffargue, P., Mortensen, L. O. et al. 2016. Estimating seabed pressure from demersal trawls, seines, and dredges based on gear design and dimensions. ICES Journal of Marine Science, 73: i27-43.

Eigaard, O. R., Bastardie, F., Hintzen, N. T., Buhl-Mortensen, L., Buhl-Mortensen, P., Catarino, R., Dinesen, G. E. et al. 2017. The footprint of bottom trawling in European waters: distribution, intensity, and seabed integrity. ICES Journal of Marine Science, 74: 847-865.

Gogina, M., Nygård, H., Blomqvist, M., Daunys, D., Josefson, A. B., Kotta, J., Maximov, A. et al. 2016. The Baltic Sea scale inventory of benthic faunal communities. ICES Journal of Marine Science, 73: 1196-1213.

Gray, J. S., Wu, R. S., and Or, Y. Y. 2002. Effects of hypoxia and organic enrichment on the coastal marine environment. Marine Ecology Progress Series, 238: 249-279.

Hansson, M., Lindegarth, M., Valentinsson, D., and Ulmestrand, M. 2000. Effects of shrimp-trawling on abundance of benthic macrofauna in Gullmarsfjorden, Sweden. Marine Ecology Progress Series, 198: 191-201.

Hiddink, J. G., Jennings, S., Sciberras, M., Bolam, S. G., Cambiè, G., McConnaughey, R. A., Mazor, T. et al. 2019. Assessing bottom-trawling impacts based on the longevity of benthic invertebrates. Journal of Applied Ecology, 56: 1075-1084.

Hiddink, J. G., Jennings, S., Sciberras, M., Szostek, C. L., Hughes, K. M., Ellis, N., Rijnsdorp, A. D. et al. 2017. Global analysis of depletion and recovery of seabed biota after bottom trawling disturbance. Proceedings of the National Academy of Sciences, 114: 8301-8306.

ICES. 2017. HELCOM request on the production of spatial data layers of fishing intensity/pressure, doi: 10.17895/ices.advice.468.

Jenkins, C. 1997. Building offshore soils databases. Sea Technology, 38: 25-28.

Kaiser, M. J., Hormbrey, S., Booth, J. R., Hinz, H., and Hiddink, J. G. 2018. Recovery linked to life history of sessile epifauna following exclusion of towed mobile fishing gear. Journal of Applied Ecology, 55: 1060-1070.

Korpinen, S., Meski, L., Andersen, J. H., and Laamanen, M. 2012. Human pressures and their potential impact on the Baltic Sea ecosystem. Ecological Indicators, 15: 105-114. 
Levin, L. A., Ekau, W., Gooday, A. J., Jorissen, F., Middelburg, J. J., Naqvi, S. W. A., Neira, C. et al. 2009. Effects of natural and human-induced hypoxia on coastal benthos. Biogeosciences, 6: 2063-2098.

Mazor, T. K., Pitcher, C. R., Ellis, N., Rochester, W., Jennings, S., Hiddink, J. G., McConnaughey, R. A. et al. 2017. Trawl exposure and protection of seabed fauna at large spatial scales. Diversity and Distributions, 23: 1280-1291.

Pitcher, C. R., Ellis, N., Jennings, S., Hiddink, J. G., Mazor, T., Kaiser, M. J., Kangas, M. I. et al. 2017. Estimating the sustainability of towed fishing-gear impacts on seabed habitats: a simple quantitative risk assessment method applicable to data-limited fisheries. Methods in Ecology and Evolution, 8: 472-480.

Rijnsdorp, A. D., Bastardie, F., Bolam, S. G., Buhl-Mortensen, L., Eigaard, O. R., Hamon, K. G., Hiddink, J. G. et al. 2016. Towards a framework for the quantitative assessment of trawling impact on the seabed and benthic ecosystem. ICES Journal of Marine Science, 73: i127-138.

Rijnsdorp, A. D., Bolam, S. G., Garcia, C., Hiddink, J. G., Hintzen, N. T., van Denderen, D. P., and Van Kooten, T. 2018. Estimating sensitivity of seabed habitats to disturbance by bottom trawling based on the longevity of benthic fauna. Ecological Applications, 28: 1302-1312.

Rijnsdorp, A. D., Buys, A. M., Storbeck, F., and Visser, E. G. 1998. Micro-scale distribution of beam trawl effort in the southern North Sea between 1993 and 1996 in relation to the trawling frequency of the sea bed and the impact on benthic organisms. ICES Journal of Marine Science, 55: 403-419.

Schernewski, G., Friedland, R., Carstens, M., Hirt, U., Leujak, W., Nausch, G., Neumann, T. et al. 2015. Implementation of European marine policy: new water quality targets for German Baltic waters. Marine Policy, 51: 305-321.

Sciberras, M., Hiddink, J. G., Jennings, S., Szostek, C. L., Hughes, K. M., Kneafsey, B., Clarke, L. J. et al. 2018. Response of benthic fauna to experimental bottom fishing: a global meta-analysis. Fish and Fisheries, 19: 698-715.

Sciberras, M., Parker, R., Powell, C., Robertson, C., Kröger, S., Bolam, S., and Hiddink, J. G. 2016. Impacts of bottom fishing on the sediment infaunal community and biogeochemistry of cohesive and non-cohesive sediments. Limnology and Oceanography, 61: 2076-2089.

Sköld, M., Göransson, P., Jonsson, P., Bastardie, F., Blomqvist, M., Agrenius, S., Hiddink, J. G. et al. 2018. Effects of chronic bottom trawling on soft-seafloor macrofauna in the Kattegat. Marine Ecology Progress Series, 586: 41-55.
Tillin, H. M., Hiddink, J. G., Jennings, S., and Kaiser, M. J. 2006. Chronic bottom trawling alters the functional composition of benthic invertebrate communities on a sea-basin scale. Marine Ecology Progress Series, 318: 31-45.

Törnroos, A., and Bonsdorff, E. 2012. Developing the multitrait concept for functional diversity: lessons from a system rich in functions but poor in species. Ecological Applications, 22: 2221-2236.

Törnroos, A., Bonsdorff, E., Bremner, J., Blomqvist, M., Josefson, A. B., Garcia, C., and Warzocha, J. 2015. Marine benthic ecological functioning over decreasing taxonomic richness. Journal of Sea Research, 98: 49-56.

Valanko, S., Norkko, A., and Norkko, J. 2010. Strategies of post-larval dispersal in non-tidal soft-sediment communities. Journal of Experimental Marine Biology and Ecology, 384: 51-60.

van Denderen, P. D., Bolam, S., Hiddink, J., Jennings, S., Kenny, A., Rijnsdorp, A., and van Kooten, T. 2015. Similar effects of bottom trawling and natural disturbance on composition and function of benthic communities across habitats. Marine Ecology Progress Series, 541: 31-43.

van Denderen, P. D., Hintzen, N. T., Van Kooten, T., and Rijnsdorp, A. D. 2015. Temporal aggregation of bottom trawling and its implication for the impact on the benthic ecosystem. ICES Journal of Marine Science, 72: 952-961.

van Denderen, P. D., van Kooten, T., and Rijnsdorp, A. D. 2013. When does fishing lead to more fish? Community consequences of bottom trawl fisheries in demersal food webs. Proceedings of the Royal Society B: Biological Sciences, 280: 20131883.

Vaquer-Sunyer, R., and Duarte, C. M. 2008. Thresholds of hypoxia for marine biodiversity. Proceedings of the National Academy of Sciences, 105: 15452-15457.

Villnäs, A., Hewitt, J., Snickars, M., Westerbom, M., and Norkko, A. 2018. Template for using biological trait groupings when exploring large-scale variation in seafloor multifunctionality. Ecological Applications, 28: 78-94.

Villnäs, A., Norkko, J., Lukkari, K., Hewitt, J., and Norkko, A. 2012. Consequences of increasing hypoxic disturbance on benthic communities and ecosystem functioning. PLoS One, 7: e44920.

Watson, R. A., and Tidd, A. 2018. Mapping nearly a century and a half of global marine fishing: 1869-2015. Marine Policy, 93: 171-177.

Whitlatch, R. B., Lohrer, A. M., Thrush, S. F., Pridmore, R. D., Hewitt, J. E., Cummings, V. J., and Zajac, R. N. 1998. Scale-dependent benthic recolonization dynamics: life stage-based dispersal and demographic consequences. Hydrobiologia, 375: 217-226. 